\title{
Insect herbivory in novel Quercus ilex L. forests: the role of landscape attributes, forest composition and host traits
}

\author{
Helena Ruiz-Carbayo ${ }^{1} \cdot$ Joan Pino $^{1,2} \cdot$ Raúl Bonal $^{3} \cdot$ Patrick M. A. James $^{4} \cdot$ Arndt Hampe $^{5} \cdot$ Roberto Molowny-Horas $^{1}$. \\ Josep Maria Espelta ${ }^{1,2}$
}

Received: 17 October 2019 / Accepted: 24 February 2020 / Published online: 24 March 2020

(C) INRAE and Springer-Verlag France SAS, part of Springer Nature 2020

\begin{abstract}
- Key message Insect herbivory in novel Quercus ilex L. forests is a highly context- and scale-dependent process. We show that forest composition, tree height and fine-scale spatial location, as well as tree genetic relatedness and ontogeny, can all influence herbivore activity at local to landscape scale.

- Context Understanding the intrinsic and extrinsic drivers of herbivory in novel expanding forests is essential to envisage their role for biodiversity conservation.

- Aims To analyse the effects of landscape attributes, forest composition, genetic relatedness, ontogeny and leaf traits on insect herbivory in novel $Q$. ilex forest stands.

- Methods In 15 forest patches, we examined effects of patch size and connectivity, forest composition, tree height, specific leaf area (SLA) and nitrogen content on herbivory. In 3 forest patches, we assessed effects of tree genetic relatedness, ontogeny and spatial distribution.

- Results Herbivory was lower in pine-oak than in mixed-oak forests owing to the shorter tree height in the former with no effects of patch size or connectivity. Herbivory increased with SLA whereas nitrogen content had no effect. Within patches, herbivory differed among genetic clusters and was reduced in saplings growing near mature oaks and individuals near the forest edge.

- Conclusion We illustrate the strong context and scale dependence of tree-herbivore interactions that renders predictions for dynamic systems such as novel oak forests extremely challenging. It implies, however, that the structural heterogeneity of such unmanaged forests allows their function as stepping stones for insect herbivore diversity in fragmented landscapes.
\end{abstract}

Keywords Connectivity · Forest expansion $\cdot$ Genetic relatedness $\cdot$ Leaf nitrogen content $\cdot$ Specific leaf area

Handling Editors: Arndt Hampe; Irene Martín-Forés; Raquel AlfaroSánchez

Contributions of the co-authors H.R-C, J.P, R.B and J.M.E conceived and designed the research; H.R-C and J.M.E collected the field data; P.AM.J, A.H and R. M-H assisted with the analyses; H.R-C, A.H and J.M.E led the writing of the manuscript. All co-authors were involved in revising and editing the manuscript.

This article is part of the topical collection on Establishment of secondgrowth forests in human landscapes: ecological mechanisms and genetic consequences

Josep Maria Espelta

josep.espelta@uab.cat

Helena Ruiz-Carbayo

helena_carbayo@hotmail.com

Joan Pino

Joan.Pino@uab.cat

Raúl Bonal

raulbonal@unex.es
Patrick M. A. James

patrick.james@utoronto.ca

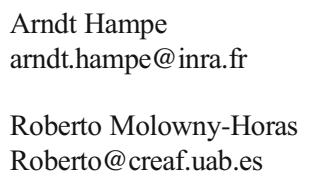

Extended Author affiliation available at the last page of the article 


\section{Introduction}

Although deforestation is still a major environmental threat at a global scale (Song et al. 2018), massive forest expansion on former agricultural lands has occurred in Europe during the twentieth century as a consequence of the widespread abandonment of rural areas, a process expected to continue in the near future (Kauppi et al. 2018). For example, in France, forest surface increased by $35 \%$ since 1945 and is estimated to grow 30.000 ha yearly (Tissot and Kohler 2013), while in Spain, forests established after 1950 already account for $25 \%$ of the current forest area (Vilà-Cabrera et al. 2016). Several studies have highlighted the crucial role that these second-growth forests may have in providing key ecosystem services such as increasing carbon stocks (Pugh et al. 2019) or landscape defragmentation (Perino et al. 2019). Yet, less attention has been paid on how communities and trophic interactions are assembled in novel forests, despite the relevance of this process for biodiversity conservation. Novel forest patches established in fragmented rural landscapes tend to be smaller than pre-existing ones in their surroundings, to experience strong edge effects and to show differences in species composition owing to a transient surplus or deficit (e.g. Basnou et al. 2016 for plants; Ruíz-Carbayo et al. 2016 for Lepidoptera). As a result of land use legacies, they may also show differences in functional traits, such as lower specific leaf area (R. Guerreri, unpublished results), lower wood density (Alfaro-Sánchez et al. 2019) or higher leaf nitrogen content (Freschet et al. 2014). Finally, novel forests may show reduced tree genetic diversity as they typically establish from a few founder trees that dominate the local regeneration (Hampe et al. 2013; Gerzabek et al. 2017).

Phytophagous insects are often among the first organisms to colonize novel forests, (Lawton 1983) and herbivory is one of the main plant-animal interactions that may shape their dynamics by reducing plant fitness (Maron and Crone 2006; Canelo et al. 2018). Herbivory has been recognized to be a complex phenomenon influenced by factors that determine plant accessibility (e.g. habitat connectivity, host appearance) and attractiveness (e.g. palatability) for herbivores. At the landscape level, herbivory has commonly been claimed to be influenced by patch isolation, patch size and forest composition. Thus, more connected and larger forest patches often harbour a more diverse and abundant herbivore community because they can be more easily colonized and offer better quality resources (Tscharntke et al. 2002; Maguire et al. 2015; Valdés-Correcher et al. 2019). Concerning forest composition, herbivory tends to be lower in mixed forests, especially when taxonomically distant tree species co-exist (Jactel and Brockerhoff 2007). At the within-patch level, it has been shown that herbivory may be driven by intrinsic host tree characteristics such as genetic identity and ontogeny as well as by extrinsic features such as the location of the tree relative to its neighbours or to the edge of the patch. Susceptibility to herbivory can vary among host genotypes owing to differences in the expression of phenotypic traits that affect insect feeding preference, such as plant architecture or leaf palatability (Castagneyrol et al. 2012; Moreira et al. 2014; Barbour et al. 2015; Lämke and Unsicker 2018). In addition, ontogenetic shifts in architecture and defence traits as plant grow influence herbivory (Boege and Marquis 2005; Moreira et al. 2017). These effects may be modified by associational effects that arise from interactions with conspecific or heterospecific neighbours (Barbosa et al. 2009; Moreira et al. 2016; Castagneyrol et al. 2019) with the sign of this interaction depending on host-neighbour differences in leaf palatability (Moreira et al. 2016), the emission of volatile signalling compounds (Karban et al. 2006; Moreira et al. 2017) or the architecture and "apparency" of the focal plant (Boege 2005; Boege and Marquis 2005). Finally, the location of the host from the forest edge may influence host traits (e.g. leaf palatability: Onoda et al. 2008), the abundance of herbivores and their enemies (Pare and Tumlinson 1999; Cadenasso and Pickett 2000; McGeoch and Gaston 2000; Skoczylas et al. 2007), thereby influencing herbivory extent.

Although it has been broadly acknowledged that levels of herbivory result from complex interactions among scaledependent ecological features (e.g. Bagchi et al. 2018; Lämke and Unsicker 2018), up to now, the few available studies explicitly conducted on herbivory in novel forest patches have focused on their landscape arrangement. For example, Valdés-Correcher et al. (2019) reported for expanding Quercus robur L. forests that patch size and connectivity modified the guild of herbivores and their predators but had a minor effect on herbivory. Ruíz-Carbayo et al. (2016) showed that the abundance and diversity of Lepidoptera varied with the size, age and connectivity of Quercus ilex trees recently established in croplands. Ultimately, such changes in the community of insects resulted in differences in the extent of herbivory among new patches depending on their connectivity (Ruíz-Carbayo et al. 2018). Notwithstanding their interest, the previous studies failed to provide mechanistic explanations of the reported differences, as they ignored the potential role played by within-patch variation and, more specifically, host attributes (genetic identity, ontogeny or functional traits). Thus, the main aim of the present study is to dissect the effects of forest patch composition, host genetic identity, ontogeny and leaf traits (SLA and nitrogen content) on insect leaf herbivory in holm oak (Quercus ilex L.) trees growing in novel forest patches. In particular, we address the following questions: (i) Is herbivory in $Q$. ilex trees triggered by patch-level characteristics of novel forests? (ii) Does individual variation in tree architecture or leaf functional traits trigger within-patch patterns of herbivory? And (iii) which role do the genetic relatedness, ontogeny and spatial location of trees within their population play for within-patch variation in herbivory? 
Finally, we discuss the implications of our results for the management of novel forest patches towards the maintenance of biodiversity in highly anthropogenised landscapes.

\section{Material and methods}

\subsection{Study area and selection of novel forest patches}

The research was carried out in the Vallès lowland (Barcelona, Spain, $41^{\circ} 33^{\prime} \mathrm{N}, 2^{\circ} 2^{\prime} \mathrm{E}$, Fig. 1). The region has a Mediterranean climate with annual rainfall averaging $650 \mathrm{~mm}$ and a mean temperature range from $6{ }^{\circ} \mathrm{C}$ in winter to $23^{\circ} \mathrm{C}$ in summer. The area harbours a large number of new forest patches spontaneously established after 1950 on former croplands (Guirado et al. 2008). Holm oak is the dominant oak in many of these patches where is accompanied by other tree species such as Pinus halepensis Mill., P. pinea L., Q. suber L. and $Q$. pubescens Willd. Holm oak hosts a diverse community of insect herbivores including the caterpillars of specialist Lepidoptera (Ruíz-Carbayo et al. 2016). Defoliation by insects in this species has been observed to affect regeneration by reducing acorn production (Canelo et al. 2018).

We addressed our research questions through two complementary studies conducted in a total of 18 forest patches that had established on former croplands after 1956. These patches were identified by combining two land cover maps obtained after photo-interpretation of 1956 and 2005 orthoimages (see Basnou et al. 2016). All selected patches contained a cover of Q. ilex trees higher than 70\% (Ruiz-Carbayo et al. 2020).

\subsection{Study I: Effects of patch attributes, forest composition and tree functional traits on insect herbivory}

For this study, we selected 15 patches harbouring the two most abundant forest types in the study area according to Guirado et al. (2008): mixed $P$. halepensis- $Q$. ilex (hereafter pine-oak) forests ( 8 patches) and mixed $Q$. pubescens- $Q$. ilex (hereafter mixed oak) forests (7 patches). For each patch, we determined the area and the connectivity by setting a $1-\mathrm{km}$ radius buffer around in which we calculated the forest cover percentage. We constrained the calculation to this radius because forest patches in the study area are rarely isolated from each other by a larger distance (Ruíz-Carbayo et al. 2018). In each patch, we randomly established a plot with a radius of $8 \mathrm{~m}$ and counted all individuals in the tree layer, identified the species and measured height and diameter at breast height (dbh) of all individuals with a dbh $>3 \mathrm{~cm}$. Then, we haphazardly selected 30 Q. ilex trees from across the patch and collected 30 fully sun-exposed leaves from the canopy top of each tree to determine mean insect herbivory and another ten healthy leaves per tree (i.e. without traces of herbivore or pathogen damages) to determine specific leave area (SLA) and leaf nitrogen (\%) content. Mean herbivory per tree was estimated by scanning the leaves, quantifying the total leaf area consumed by insects and dividing it by the total leaf area of the 30 leaves collected, a commonly used procedure. No attempt was made to distinguish different insect guilds as the vast majority of damage was caused by chewers. For the calculation of SLA, leaf area was determined after scanning the ten leaves and dry weight was obtained after placing them for $72 \mathrm{~h}$ in an oven at $60^{\circ} \mathrm{C}$.
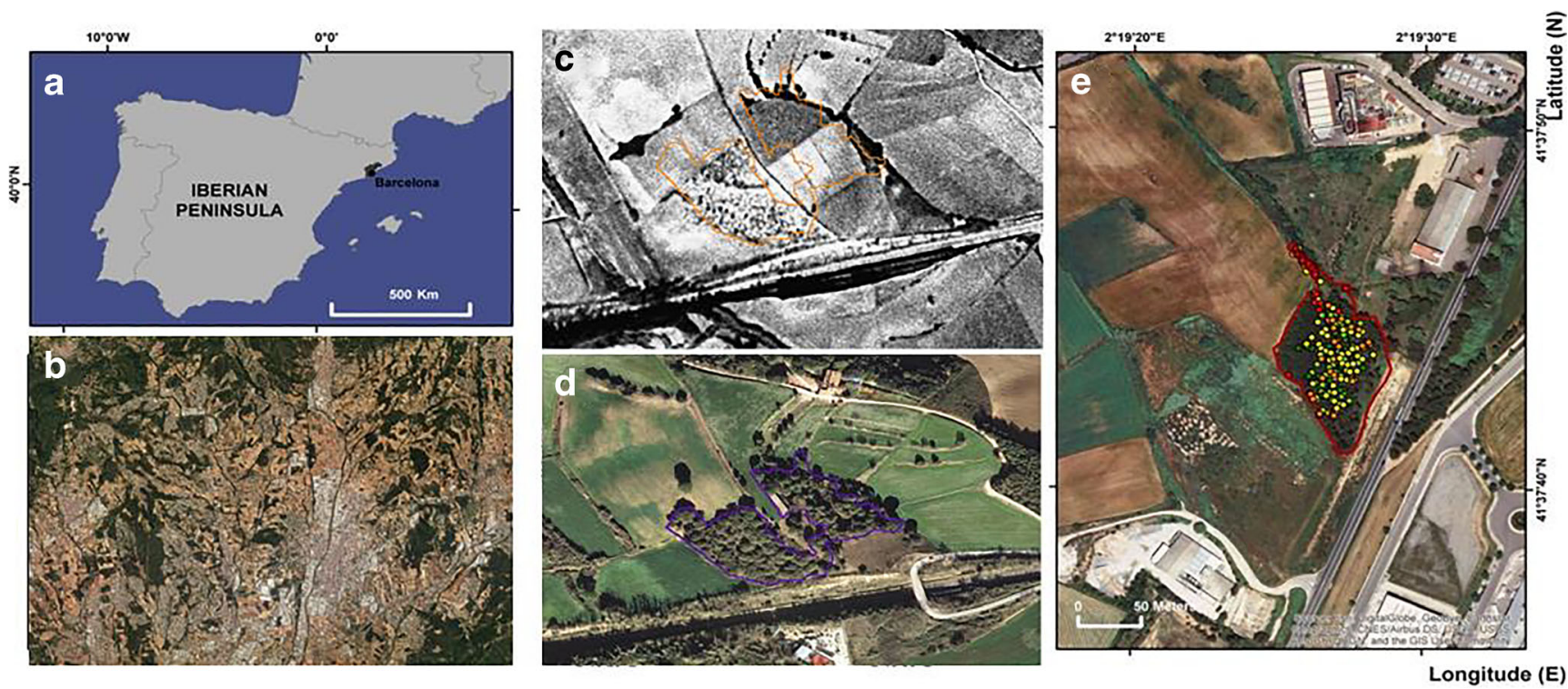

Fig. 1 a General location of the study area. b The Vallés lowland is a highly anthropogenised mosaic-like landscape with disseminated forest patches. c, d Historical (1956) and recent (2009) view of a sampled forest patch. e Oaks of the five different age classes sampled (see Section 2) are represented by coloured points. Class 1 , yellow; class 2 , light green; class 3 , dark green; class 4 , orange and class 5 , red 
The dried leaves were then finely grinded and placed into tin capsules (Sn 98 capsules, Lüdiswiss, Flawil, Switzerland) to analyse N content. Analyses were carried out at the UC Davis Stable Isotope Facility, with a Finnigan MAT Delta PlusXL IRMS. The main structural characteristics of the 15 forest patches and mean values of SLA, leaf N content and herbivory are shown in Table 1. Concerning landscape and structural variables, the two forests types only differed in a shorter average height of $Q$. ilex trees in the pine-oak forests (MannWhitney, $z=-2.985, P=0.027)$.

\subsection{Study II: Effects of tree genetic identity, ontogeny and spatial distribution on insect leaf herbivory}

For this study, we selected three forest patches (Cardedeu, Martorell and Cervelló) with an abundant presence of $Q$. ilex and an inter-patch distance between 9.2 and $37.3 \mathrm{~km}$ (Table 2). We identified all holm oaks within each patch and classified them into five size categories: (1) seedlings less than $20 \mathrm{~cm}$ in height, (2) seedlings 20-50 cm, (3) small saplings $50-130 \mathrm{~cm}$, (4) saplings larger than $130 \mathrm{~cm}$ in height but with $\mathrm{dbh}<5 \mathrm{~cm}$ and (5) mature individuals with $\mathrm{dbh} \geq 5 \mathrm{~cm}$ (see Fig. 1). Then, we selected a total of 200 individuals per patch using a stratified design to ensure a sufficient sample size for each category. We mapped each individual, measured its basal diameter (as a proxy of size) and collected a random sample of up to 30 leaves for measuring herbivory as described above. For an accurate determination of the age, we harvested seedlings and small saplings to get a trunk disc or extracted a core from the trunk in larger individuals using a Pressler borer. These samples were used for counting annual growth rings as described in Alfaro-Sánchez et al. (2019). The main characteristics of the three forest patches are summarized in Table 2 .

All oaks were genotyped using 66 SNP (singlenucleotide polymorphism) loci (Bonal et al. 2019) that were combined into two multiplexes and sequenced on an iPLEX Gold genotyping kit (Sequenom, San Diego, CA, USA) following the procedure described in Chancerel et al. (2013). The data analysis was completed using MassARRAY Typer Analyser 4.0.26.75 (Agena Biosciences). We used the resulting genotypic data to calculate the heterozygosity of each tree by dividing the number of heterozygous loci by the total number of loci amplified. Then, we performed a cluster analysis using the find.clusters function of the adegenet package (Jombart et al. 2010). The identified genetic clusters were subsequently included in the linear mixed models as a fixed factor to test for effects of genetic relatedness (here defined as membership in a given cluster) on herbivory.

We used two measures to test for spatial position effects. First, we calculated the distance to the nearest mature holm oak for all sampled seedlings and saplings (i.e. age categories 1 to 4 ) using the Euclidean distance as implemented by the distance function in the package ecodist in $\mathrm{R}$ version 3.4.1. ( $\mathrm{R}$ Core Team 2017). Second, we computed the average distance to every mature tree within the patch and used the inverse of this quantity as a proxy for within-patch spatial connectivity. Third, we calculated the distance to the patch edge by rasterizing the vector layers that contained the individual locations and the polygons of the sampling patches (with $\mathrm{R}$ packages rgeos, rgdal and raster) and calculating the minimum distance to the polygon border.

\subsection{Statistical analysis}

The relationship of herbivory (log transformed) with forest type, patch size and connectivity in the study I was explored by means of a general linear mixed effects model including patch as a random effect. We removed all interactions among fixed factors (considered up to the 2 nd degree) that were not significant from the saturated model. Then, we implemented a path analysis (Sokal and Rohlf $1995)$ to infer causal connections between different potentially interconnected variables and herbivory in the two different forest types. The diagram in Fig. 2 shows the causal relations we tested in our multivariate model. We considered forest type (mixed pine-oak and mixed-oak forests) as an exogenous variable whose variance was assumed to be caused by variables not included in the model (and therefore not tested). Examples of such an exogenous effect could obey to differences in the abundance and composition of the community of insects feeding upon oak mediated by differences in forest composition. Then, we considered four endogenous variables: (i) tree height (as a proxy of apparency to herbivores), (ii) SLA (as a proxy of leaf palatability), (iii) leaf $\mathrm{N}$ content and (iv) log transformed mean herbivory. Thus, we compared the direct effects of height, SLA, $\% \mathrm{~N}$ and forest type on herbivory, with the indirect effect of forest type through the other three variables. Although it is well known that plant height may influence SLA owing to the effects of shading, we did not include this relationship in our path analysis as all sampled leaves had been collected from the upper part of the tree canopy and fully sun exposed.

Prior to running the statistical analyses in the study II, we checked for collinearity among continuous predictors using Pearson's correlation coefficients. Since basal diameter and age (inferred from the dendrochronological analyses) presented an $r$ value higher than 0.6, we discarded size from subsequent analyses. Therefore, we proceeded with a generalized linear model (GLM) to characterise the effects of site, oak genetic relatedness (cluster identify), heterozygosity, age, distance to the forest edge and distance to mature oaks. We built a saturated model with herbivory as a response variable and all 


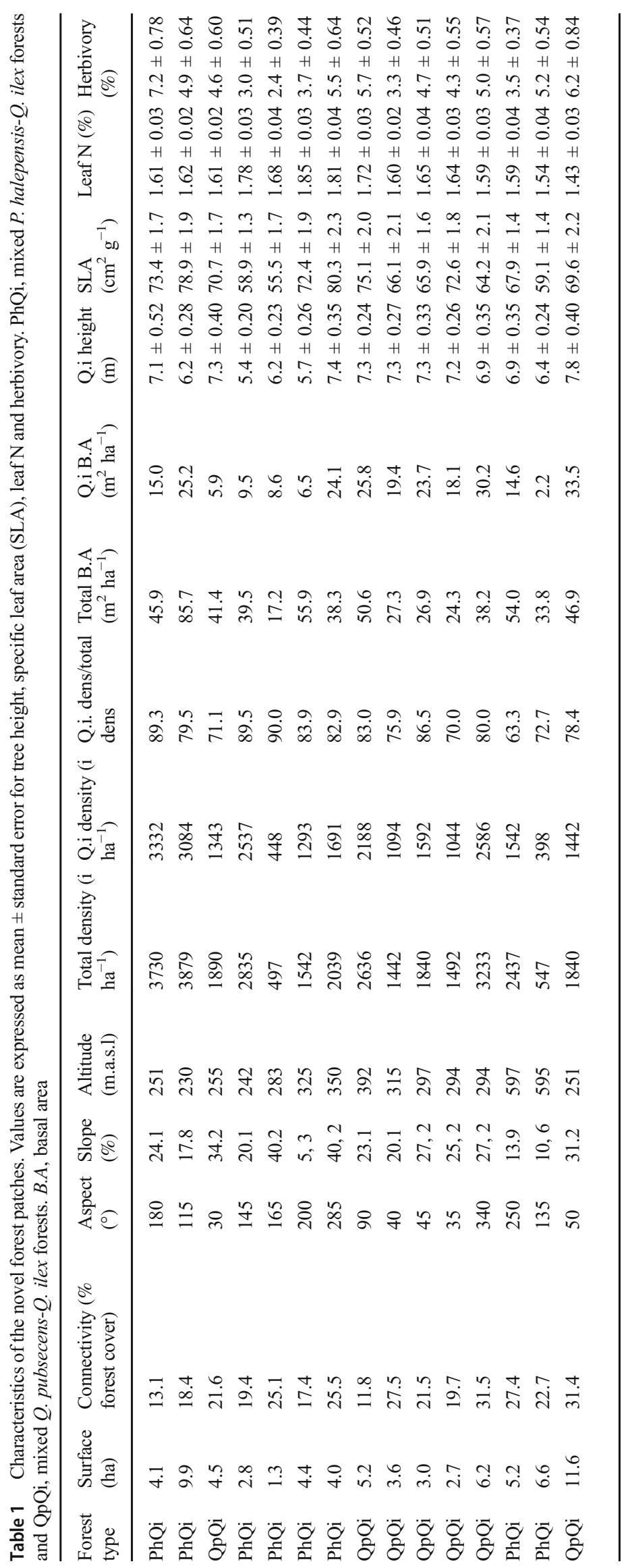


Table 2 Summary table of oak characteristics and herbivory damage per size category class at the three forest patches (Cardedeu, Martorell and Cervelló) where intra-patch differences in herbivory were analysed. Numeric variables are expressed as mean \pm standard error. \% heterozygosity refers to single-nucleotide polymorphism (SNP) loci. Genetic cluster indicates the percentage of individuals assigned to one of the five clusters identified (see Section 3). Distance to mature oaks is the inverse of the mean distance. Herbivory is expressed as the $\%$ of leaf surface consumed (see Section 2 for further details)

\begin{tabular}{|c|c|c|c|c|c|c|c|c|c|c|c|c|c|}
\hline \multirow[t]{2}{*}{ Site } & \multirow[t]{2}{*}{ UTM_X } & \multirow[t]{2}{*}{ UTM_Y } & \multirow{2}{*}{$\begin{array}{l}\text { Size } \\
\text { category }\end{array}$} & \multirow{2}{*}{$\begin{array}{l}\text { Age } \\
\text { (years) }\end{array}$} & \multirow{2}{*}{$\begin{array}{l}\% \\
\text { heterozygosity }\end{array}$} & \multicolumn{5}{|c|}{ Genetic cluster $(\%)$} & \multirow{2}{*}{$\begin{array}{l}\text { Distance to } \\
\text { edge }(m)\end{array}$} & \multirow{2}{*}{$\begin{array}{l}\text { Connectivity } \\
\left(\mathrm{m}^{-1}\right)\end{array}$} & \multirow{2}{*}{$\begin{array}{l}\text { Herbivory } \\
(\%)\end{array}$} \\
\hline & & & & & & 1 & 2 & 3 & 4 & 5 & & & \\
\hline \multirow[t]{5}{*}{ Cardedeu } & \multirow[t]{5}{*}{$443,704.362$} & \multirow[t]{5}{*}{$4,608,785.4$} & 1 & $2.4 \pm 1.2$ & $0.29 \pm 0.11$ & 45 & 10 & 0 & 2 & 43 & $21.5 \pm 8.4$ & $0.0040 \pm 0.0004$ & $10.1 \pm 8.9$ \\
\hline & & & 2 & $4.7 \pm 1.5$ & $0.26 \pm 0.10$ & 38 & 7 & 14 & 14 & 27 & $21.2 \pm 9.8$ & $0.0041 \pm 0.0004$ & $7.5 \pm 6.3$ \\
\hline & & & 3 & $10.7 \pm 3.0$ & $0.24 \pm 0.08$ & 68 & 5 & 0 & 20 & 7 & $22.4 \pm 9.1$ & $0.0059 \pm 0.0003$ & $3.2 \pm 3.5$ \\
\hline & & & 4 & $17.6 \pm 4.3$ & $0.23 \pm 0.06$ & 52 & 3 & 21 & 21 & 3 & $17.4 \pm 8.3$ & $0.0065 \pm 0.0010$ & $1.6 \pm 1.6$ \\
\hline & & & 5 & $19.8 \pm 5.2$ & $0.24 \pm 0.08$ & 5 & 5 & 45 & 30 & 15 & $4.4 \pm 4.1$ & $0.0060 \pm 0.0004$ & $3.1 \pm 0.2$ \\
\hline \multirow[t]{5}{*}{ Martorell } & \multirow[t]{5}{*}{$413,672.565$} & \multirow[t]{5}{*}{$4,583,290.7$} & 1 & $2.9 \pm 1.6$ & $0.21 \pm 0.06$ & 28 & 3 & 0 & 67 & 2 & $11.3 \pm 5.0$ & $0.0116 \pm 0.0053$ & $15.0 \pm 15.8$ \\
\hline & & & 2 & $4.9 \pm 1.7$ & $0.22 \pm 0.05$ & 19 & 0 & 19 & 62 & 0 & $12.8 \pm 6.3$ & $0.0116 \pm 0.0056$ & $14.2 \pm 15.3$ \\
\hline & & & 3 & $7.9 \pm 2.9$ & $0.20 \pm 0.07$ & 22 & 0 & 8 & 70 & 0 & $12.4 \pm 5.8$ & $0.0128 \pm 0.0068$ & $7.2 \pm 4.7$ \\
\hline & & & 4 & $13.4 \pm 5.3$ & $0.22 \pm 0.07$ & 10 & 0 & 3 & 84 & 3 & $16.0 \pm 5.0$ & $0.0133 \pm 0.0044$ & $5.7 \pm 7.2$ \\
\hline & & & 5 & $23.0 \pm 5.9$ & $0.25 \pm 0.05$ & 16 & 0 & 32 & 52 & 0 & $17.0 \pm 5.4$ & $0.0386 \pm 0.0097$ & $2.1 \pm 0.3$ \\
\hline \multirow[t]{5}{*}{ Cervelló } & \multirow[t]{5}{*}{$408,533.297$} & \multirow[t]{5}{*}{$4,593,310.0$} & 1 & $3.1 \pm 1.4$ & $0.19 \pm 0.07$ & 59 & 0 & 8 & 32 & 1 & $12.9 \pm 7.7$ & $0.0148 \pm 0.0105$ & $11.2 \pm 9.5$ \\
\hline & & & 2 & $4.7 \pm 1.6$ & $0.18 \pm 0.07$ & 57 & 4 & 4 & 35 & 0 & $9.9 \pm 6.2$ & $0.0136 \pm 0.0114$ & $5.9 \pm 5.7$ \\
\hline & & & 3 & $8.5 \pm 2.9$ & $0.20 \pm 0.05$ & 50 & 0 & 0 & 46 & 4 & $10.7 \pm 6.6$ & $0.0146 \pm 0.0114$ & $4.5 \pm 5.7$ \\
\hline & & & 4 & $15.5 \pm 4.7$ & $0.18 \pm 0.06$ & 20 & 0 & 33 & 47 & 0 & $13.7 \pm 5.8$ & $0.0178 \pm 0.0043$ & $2.8 \pm 0.9$ \\
\hline & & & 5 & $24.0 \pm 4.4$ & $0.22 \pm 0.03$ & 3 & 27 & 55 & 0 & 15 & $16.2 \pm 3.3$ & $0.0185 \pm 0.0062$ & $0.9 \pm 0.1$ \\
\hline
\end{tabular}

other variables as fixed effects plus their second-degree interactions. Model selection was performed based on the secondorder Akaike information criterion (AICc) and adjusted $R^{2}$. All statistical analyses were performed in $\mathrm{R}$ version 3.4.1. (R Core Team 2017).

\section{Results}

The general linear mixed effects model revealed a significant effect of forest type on herbivory with no effects of patch size or connectivity. Herbivory was higher in mixed-oak than in

\section{Tree height}

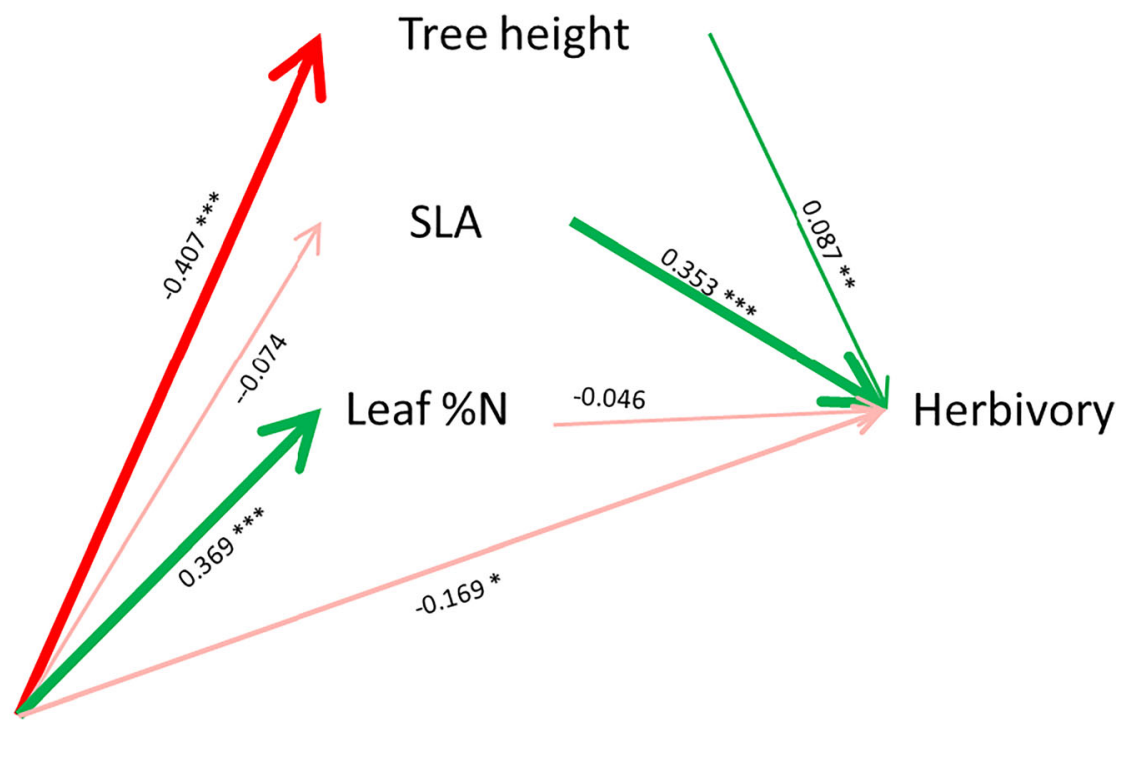

\section{Forest type (pine-oak)}

Fig. 2 Diagram showing the results of the path analyses. Green and red lines represent positive and negative correlations, respectively, while line thickness indicates the strength of the relationship. Standardised coefficients and significance thresholds $(* P<0.1, * * P<0.01$, $* * * P<0.001$, ) are shown along paths 
mixed pine-oak forests $(F=4.31, P=0.037 ; 4.82 \pm 0.23 \%$ vs. $4.05 \pm 0.22 \%)$. The model explained however a moderate amount of variance in herbivory $\left(R^{2}=0.26\right)$. The path analysis helped to establish causal connections between the different variables and confirmed differences between the two forest types (Fig. 2). Specific leaf area (SLA) was the main factor favouring herbivory (Fig. 5 in the Appendix) with a further significant, but more secondary, positive influence of tree height mediated by forest type. Forest type influenced leaf $\mathrm{N}$ content but with no consequences for herbivory, while we also observed a marginally significant direct effect of forest composition on herbivory.

Mean herbivory was $4.1 \pm 1.2 \%$ and decreased from younger to more advanced age classes in the three forest patches selected for the study of the effects of genetic relatedness, ontogeny and host location within the patch on herbivory (Table 2). The three forests showed a similar level of heterozygosity across the different age classes. Following the maximum parsimony principle, the most likely number of clusters present in the three study sites was five $(\Delta \mathrm{BIC}=5.8$; Table 3 in the Appendix). As shown in Table 2, the five clusters were present in the three patches, although clusters 2 and 5 were scarcely represented in Martorell and Cervelló.

The best linear mixed model for herbivory included site, genetic cluster, minimum distance to the forest edge, age class, average distance to mature oaks and the interaction between age class and distance (Table 4 in the Appendix). Herbivory was higher in the Martorell forest patch (GLM; $z=9.25 ; P=$ 0.0085 ) and this effect was observed in all age classes (Table 2). Concerning genetic characteristics, the model revealed that trees from cluster 3 were generally less affected by herbivores than those from clusters 1 and 5 (GLM; $z=-$ 7.13; $P=0.0122$ and $z=-4.15 ; P=0.0203$, respectively; Fig. 3). We also found that individuals located near the core of the forest patch exhibited more herbivory than oaks near the edge (GLM: $z=4.205 ; P=0.0304$ ). In addition to this patchlevel effect, there was a significant effect of the interaction between age and distance to mature oaks (GLM; $z=-$ 4.188; $P<0.001)$ : Herbivory was lower in individuals closer to mature oaks but only above a certain developmental threshold (i.e. in saplings but not in seedlings; Fig. 4).

\section{Discussion}

Understanding the mechanisms that shape plant-animal interactions in second-growth forests is essential to design sound management practices to ensure the role of these novel habitats in biodiversity conservation. In this sense, the first contribution of our study is to show that tree species composition of the patch may play a stronger role for insect herbivory than standard landscape-scale predictors such as its size and connectivity. Second, this is, to the best of our knowledge, one of the very few studies conducted under natural conditions to show that differences in herbivory damage may be related with host genetic relatedness. Third, we show that finegrained spatial aspects such as the distribution of individuals, their size as reflected by the developmental stage and their distance from the forest edge are also relevant for the extent of herbivory. Overall, these results represent a neat illustration of the extensive context and scale dependence of plant-insect herbivore interactions in natural settings.

It has been often acknowledged that insect richness and abundance decrease in smaller and more distant forest patches (Thies et al. 2005; Andersson et al. 2013; Brudvig et al. 2017), while contrasting trends have been reported for herbivory (De Carvalho Guimarães et al. 2014; Ruíz-Carbayo et al. 2018). The absence of patch size or connectivity effects on herbivory that we observed resemble those reported for novel $Q$. robur forests in SW France (Valdés-Correcher et al. 2019) or for highly mobile insects such as moths (Cydia sp.) in Spanish novel holm oak forests (Ruíz-Carbayo et al. 2018). Many leaf chewers are mobile species whose colonisation capacity is not limited by the levels of connectivity that were investigated here. In other words, connectivity may be irrelevant in this sort of Mediterranean-type mosaic landscapes where, in spite of the general mosaic-like aspect (see Fig. 1), there are still abundant forest areas intermingled. In addition, the lack of effects could be further mediated by a stepping-stone effect (Brown and Kodric-Brown 1977) of scattered Q. ilex trees that grow in nearby hedgerows and may facilitate resources and dispersal opportunities (see Fig. $1 \mathrm{c}$ and d).

Conversely to the spatial arrangement of patches, forest composition influenced herbivory with lower levels in pineoak forests compared with mixed-oak forests. Lower

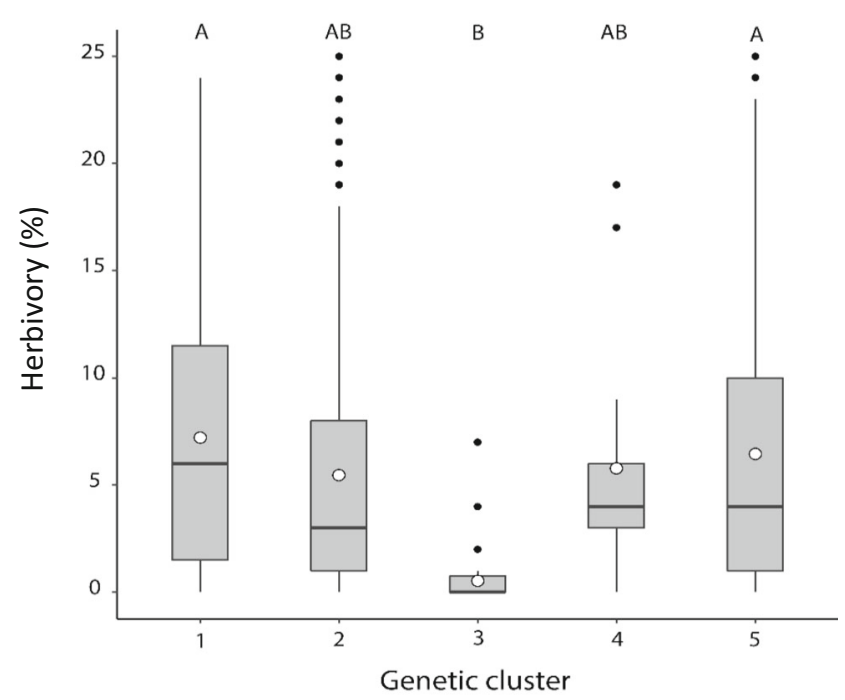

Fig. 3 Percentage of insect herbivory on the five different $Q$. ilex genetic clusters identified by successive K-means. Boxplots represent median, 25 th and 75 th percentiles, respectively. Different letters indicate significant differences between genetic clusters. Means are represented by empty dots while outliers are depicted as black dots 
Fig. 4 Interaction plot for the effects of the age of the host and its distance to mature oak trees on herbivory damage. Distance $\left(\mathrm{m}^{-1}\right)$, age (years) and herbivory $(\%)$ are centred and scaled. Herbivory scale ranges from blue (low herbivory) to red (high herbivory) colours

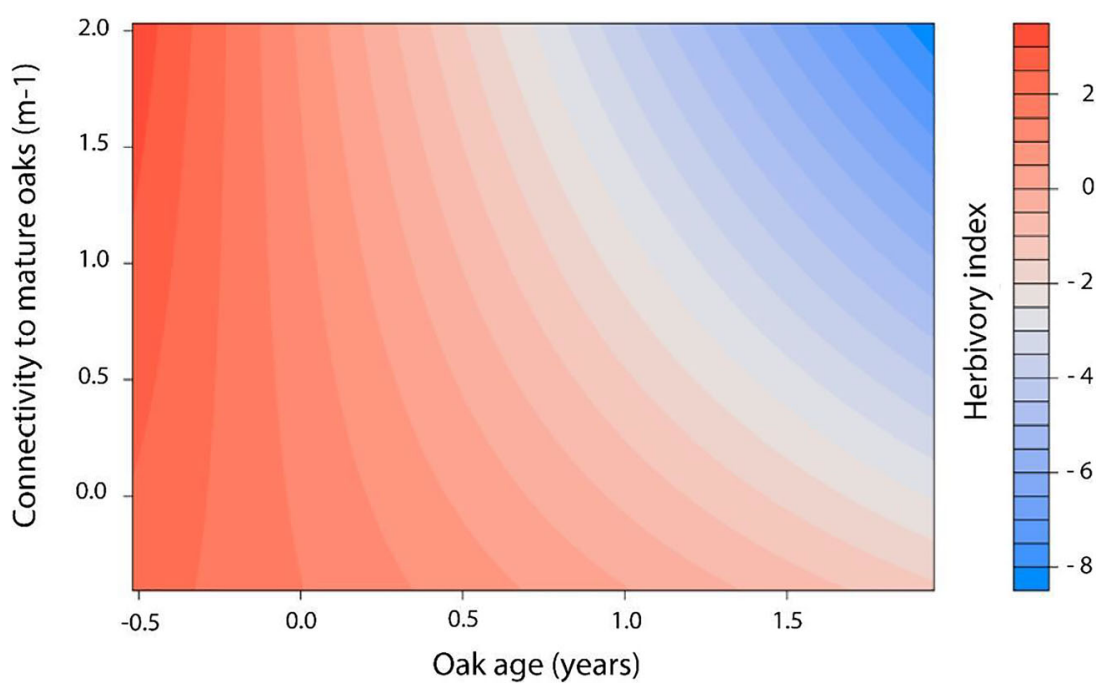

herbivory in mixed forests, especially when taxonomically distant species co-exist (such as pines and oaks), has indeed received abundant support (Jactel and Brockerhoff 2007). Our path analysis indicated moreover that this forest-type effect is, to some extent, indirect and mediated by differences in (holm oak) tree height (Fig. 2). Since we did not find any relations between forest type and SLA, we believe that the observed height effect could be more attributed to differences in the apparency of the host (Boege 2005; Castagneyrol et al. 2013; Damien et al. 2016), with shorter trees being more difficult to detect for herbivores. We cannot discard, however, that differences in tree height may also involve differences in the architecture and shape of the tree canopy, two traits suggested reducing the abundance of folivorous Lepidoptera in smaller holm oak trees (Ruíz-Carbayo et al. 2016). On the other hand, our path analysis revealed a strong effect of SLA but a negligible one of leaf $\mathrm{N}$ content (Fig. 2). The former finding is unsurprising since numerous studies have identified SLA and leaf thoroughness as a major driver of amongindividual variation in insect herbivory (Agrawal and Fishbein 2006; Pearse 2011). This trait is known to be influenced by the position of leaves and the resulting irradiation they receive - a factor that we can however discard given our sampling protocol. Specific leaf area has also been reported to vary as an adaptation of trees to local differences in water availability (Johnstone et al. 2016), which might be important in our study system with its drought-prone Mediterranean climate. In turn, the limited relevance of leaf $\mathrm{N}$ content that we observed is of particular interest in the context of novel forests as previous studies have shown that such forests tend to show elevated leaf $\mathrm{N}$ contents as a probable result of their growth on former agricultural surfaces (Freschet et al. 2014; AlfaroSánchez et al. 2019). Notwithstanding the observed effects of forest composition on herbivory, the amount of variance explained by the model was moderate (ca. 25\%). This suggests that other environmental differences among forest patches (e.g. aspect and altitude in Table 1) may also play a role in determining herbivory extent. The context dependency of herbivory and the importance of local conditions are also stressed by the higher herbivory observed in Martorell in comparison with the other two sites. These differences may arise from differences in host abundance (resource concentration) or in the particular abiotic conditions (light, temperature, humidity necessary for insect development (Bagchi et al. 2018, Ruíz-Carbayo et al. 2016, 2018).

Whereas the landscape-scale connectivity of patches, at the scale that we measured, does apparently not constrain their colonisation by herbivorous insects, we detected clear evidence that the location of host trees at a finer spatial scale (intra-patch level) affected the patterns of herbivory. A higher herbivore damage near the patch core compared with the edges has been reported in previous studies (McGeoch and Gaston 2000; Skoczylas et al. 2007; Régolini et al. 2014; Bagchi et al. 2018). Indeed, herbivore activity in forest edges may be reduced owing to harsher microclimatic conditions (e.g. lower humidity, temperature variability, greater light exposure and wind turbulences; Laurance et al. 2002; Bagchi et al. 2018). These microclimatic conditions in forest edges may also lower the quality of the resource (Baraza et al. 2004; Barber and Marquis 2011). Edges may also benefit insect enemies by facilitating the communication among parasitoids (Staudt and Lhoutellier 2007) or increasing the access of birds and other predators to adult insects and their larvae (Skoczylas et al. 2007).

In addition to the global edge effect, we found that holm oak saplings benefitted from the proximity of larger conspecifics. Differences in leaf herbivory depending on plant ontogeny have been previously reported for oaks and other species (Del-Val and Dirzo 2003; Boege and Marquis 2005; Moreira et al. 2017) and attributed to changes with ageing in leaf traits influencing herbivory (Boege and Marquis 2005), but few studies have reported interactions between individuals 
of different age or size. The fact that in our study the effect of ontogeny depended on the distance to mature oaks suggests that both ontogeny and associational effects may be strongly context dependent. One possible explanation for lower herbivory on saplings growing close to larger conspecific neighbours could be the benefit from a dilution effect whereby herbivores are satiated by a large amount of local resources, in a trend similar to that reported for monospecific oak stands (see Castagneyrol et al. 2019). That we did not detect the same trend in seedlings might be due to a simple sampling effect or to the fact that their herbivores are more strongly influenced by the immediately surrounding (including herbaceous) vegetation than in the taller saplings.

Finally, the contrasting herbivory levels observed among genetic clusters suggests that some genetically based traits (e.g. leaf structure or chemistry) might affect tree palatability and susceptibility to herbivores in these forests (see Ito and Ozaki 2005; Castagneyrol et al. 2012 for other Quercus spp.; Silfver et al. 2009 for birch). A series of possible mechanisms have been described, although the heritability of most relevant plant traits tends to be low owing to their multigenic determination and other constraints (reviewed in Büchel et al. 2016; Lämke and Unsicker 2018). However, clear evidence for effects of genetic diversity or genetic relatedness has mostly been limited to highly controlled experimental settings, whereas the relatively few studies performed in natural tree populations have largely failed to detect them (Tack et al. 2010; Gossner et al. 2015; see also the critical review by Tack et al. 2012). This scarcity of empirical evidence renders our finding noteworthy, even though a clear interpretation of the biological processes that underlay the formation of the detected clusters remains elusive.

\section{Conclusion}

Spontaneous establishment of forests in former cropland areas is a widespread phenomenon in many regions of Europe owing to rural abandonment. In novel forest patches established in Mediterranean mosaic-like landscapes, herbivory in $Q$. ilex trees seems to be shaped by some genetically based traits and different factors controlling host accessibility at different spatial scales. At the landscape level, rather than patch size or connectivity, tree species composition affects herbivory by its indirect influence on tree height, a potential proxy of host apparency. At the within-patch scale, it is the distance to mature oaks, interacting with ontogeny and the distance from the forest edge, the most relevant factors for herbivory damage. Overall, and except for the more elusive effects of genetic relatedness, our results suggest that changes induced by forest management in forest composition and fine-grained spatial distribution of oaks could significantly modify the herbivory extent in these novel forest patches.

Acknowledgements We are grateful to Jeremy Larroque, Julian Wittische and Víctor Granda for statistical advice and to Erwan Guichoux, Adline Delcamp and Yec'han Laizet for their help with SNP genotyping. We also thank Daiana Tourne, Jennifer Sauri and Raquel Ubach for their help with ArcGIS.

Funding information This research was supported by the projectsTrees4Future (FP7 284181), SPONFOREST (APCIN_2016 0174) and NEWFORLAND (RTI2018-099397-B-C22 MCIU/AEI/ ERDF, EU). H.R-C was funded by a pre-doctoral grant (BES-2013065741) from the Spanish MINECO and R.B. was funded by the program Atracción del Talento Investigador (Regional Government of Extremadura). The genotyping was performed at the Genome Transcriptome Facility of Bordeaux (Grants from Investissements d'Avenir, Convention attributive d'aide EquipEx Xyloforest ANR-10EQPX-16-01).

Data availability The datasets generated and/or analyzed during the current study are available in the Dryad repository. https://doi.org/10.5061/ dryad.rxwdbrv4v, Ruiz-Carbayo et al. 2020.

\section{Compliance with ethical standards}

Conflict of interest The authors declare that they have no conflict of interest.

\section{Appendix}

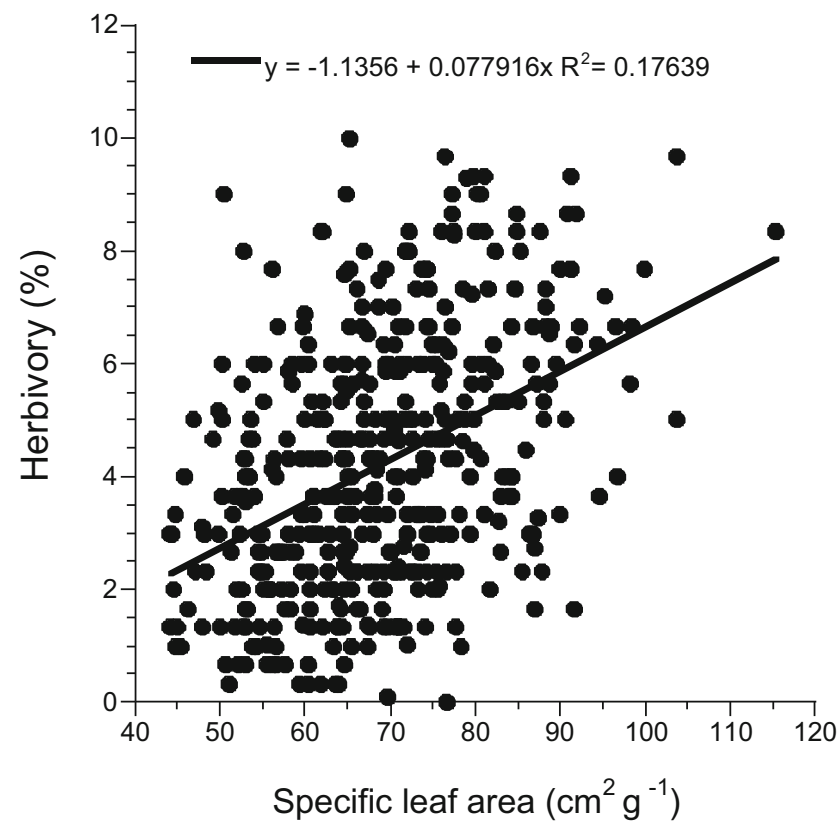

Fig. 5 Relationship between specific leaf area $\left(\mathrm{cm}^{2} \mathrm{~g}^{-1}\right)$ and herbivory (\% of leaf surface consumed) in mature oak trees in novel forest patches 
Table 3 BIC values associated with the number of genetic clusters from cluster identification using successive K-means

\begin{tabular}{ll}
\hline$K$ & BIC \\
\hline 1 & 1613.621 \\
2 & 1585.133 \\
3 & 1572.550 \\
4 & 1561.717 \\
5 & 1551.524 \\
6 & 1545.707 \\
7 & 1541.079 \\
8 & 1539.653 \\
9 & 1538.226 \\
10 & 1536.907 \\
11 & 1536.046 \\
12 & 1537.796 \\
13 & 1538.045 \\
14 & 1539.480 \\
15 & 1541.496 \\
\hline
\end{tabular}

Table 4 Selection of general linear model effects based on AIC. Saturated models include all descriptors plus their second-degree interactions (represented by an asterisk). The best model was the first showing a $\Delta$ AIC $>2$ compared with the immediately previous model in the AICranked list

\begin{tabular}{|c|c|c|c|}
\hline Response & Model & $\begin{array}{l}\text { Predictors } \\
\text { Fixed }\end{array}$ & AIC \\
\hline Herbivory & Saturated & $\begin{array}{l}\text { Site } \\
\text { Heterozygosity percentage } \\
\text { Connectivity mature oaks } \\
\text { Minimum distance to edge } \\
\text { Oak age } \\
\text { Heterozygosity percentage } * \\
\text { connectivity mature oaks } \\
\text { Heterozygosity percentage } * \\
\text { minimum distance edge } \\
\text { Heterozygosity percentage * oak age } \\
\text { Connectivity mature oaks * } \\
\text { minimum distance edge } \\
\text { Connectivity mature oaks * oak age } \\
\text { Minimum distance to edge * oak age } \\
\text { Genetic cluster }\end{array}$ & 3744.1 \\
\hline & Best & $\begin{array}{l}\text { Site } \\
\text { Genetic cluster } \\
\text { Connectivity mature oaks } \\
\text { Minimum distance edge } \\
\text { Oak age } \\
\text { Connectivity mature oaks * oak age }\end{array}$ & 3738.2 \\
\hline
\end{tabular}

\section{References}

Agrawal AA, Fishbein M (2006) Plant defense syndromes. Ecology 87: 132-149

Alfaro-Sánchez R, Jump AS, Pino J, Díez-Nogales O, Espelta JM (2019) Land use legacies drive higher growth, lower wood density and enhanced climatic sensitivity in recently established forests. Agric For Meteorol 276-277:107630

Andersson P, Löfstedt C, Hambäck PA (2013) Insect density-plant density relationships: a modified view of insect responses to resource concentrations. Oecologia 173:1333-1344

Bagchi R, Brown LM, Elphick CS, Wagner DL, Singer MS (2018) Anthropogenic fragmentation of landscapes: mechanisms for eroding the specificity of plant-herbivore interactions. Oecologia 187: $521-533$

Baraza E, Gomez J, Hodar J, Zamora R (2004) Herbivory has a greater impact in shade than in sun: response of Quercus pyrenaica seedlings to multifactorial environmental variation. Can J Bot 82:357364

Barber NA, Marquis RJ (2011) Light environment and the impacts of foliage quality on herbivorous insect attack and bird predation. Oecologia 166:401-409

Barbosa P, Hines J, Kaplan I, Martinson H, Szczepaniec A, Szendreis Z (2009) Associational resistance and associational susceptibility: having right or wrong neighbors. Annu Rev Ecol Evol Syst 40:1-20

Barbour MA, Rodriguez-Cabal MA, Wu ET, Julkunen-Tiitto R, Ritland CE, Miscampbell AE, Jules ES, Crutsinge GM (2015) Multiple plant traits shape the genetic basis of herbivore community assembly. Funct Ecol 29:995-1006

Basnou C, Vicente P, Espelta JM, Pino J (2016) Of niche differentiation, dispersal ability and historical legacies: what drives woody community assembly in recent Mediterranean forests? Oikos 125:107-116

Boege K (2005) Herbivore attack in Casearia nitida influenced by plant ontogenetic variation in foliage quality and plant architecture. Oecologia 143:117-125

Boege K, Marquis RJ (2005) Facing herbivory as you grow up: the ontogeny of resistance in plants. Trends Ecol Evol 20:441-448

Bonal R, Guichoux E, Delcamp A, Laizet Y, Hampe A (2019) 70 highly validated SNP markers for Quercus ilex. https://doi.org/10.15454/ AOVOO2. Portail Data Inra, V1

Brown JH, Kodric-Brown A (1977) Turnover rates in insular biogeography: effect of immigration on extinction. Ecology 58:445-449

Brudvig LA, Barak RS, Baur JT, Caughlin T, Laughlin DC, Larios L, Matthews JW, Stuble KL, Turley NE, Zirbel CR (2017) Interpreting variation to advance predictive restoration science. J Appl Ecol 54: 1018-1027

Büchel K, Fenning T, Gershenzon J, Hilker M, Meiners T (2016) Elm defence against herbivores and pathogens: morphological, chemical and molecular regulation aspects. Phytochem Rev 15:961-983

Cadenasso ML, Pickett STA (2000) Linking forest edge structure to edge function: mediation of herbivore damage. J Ecol 88:31-44

Canelo T, Gaytán A, González-Bornay G, Bonal R (2018) Seed loss before seed predation: experimental evidence of the negative effects of leaf feeding insects on acorn production. Integr Zool 13:238-250

Castagneyrol B, Lagache L, Giffard B, Kremer A, Jactel H (2012) Genetic diversity increases insect herbivory on oak saplings. PLoS One 7:e44247

Castagneyrol B, Giffard B, Péré C, Jactel H (2013) Plant apparency, an overlooked driver of associational resistance to insect herbivory. $\mathrm{J}$ Ecol 101:418-429

Castagneyrol B, Giffard B, Valdés-Correcher E, Hampe A (2019) Tree diversity effects on leaf insect damage on pedunculate oak: the role of landscape context and forest stratum. Forest Ecol Manag 433: 287-294

Chancerel E, Lamy JB, Lesur I, Noirot C, Klopp C, Ehrenmann F, Boury C, Le Provost G, Label P, Lalanne C, Léger V, Salin F, Gion JM, Plomion C (2013) High-density linkage mapping in a pine tree reveals a genomic region associated with inbreeding depression and provides clues to the extent and distribution of meiotic recombination. BMC Biol 11:50

Damien M, Jactel H, Meredieu C, Régolini M, van Halder I, Castagneyrol $\mathrm{B}$ (2016) Pest damage in mixed forests: disentangling the effects of 
neighbor identity, host density and host apparency at different spatial scales. For Ecol Manag 378:103-110

De Carvalho Guimarães CD, Viana JPR, Cornelissen T (2014) A metaanalysis of the effects of fragmentation on herbivorous insects. Environ Entomol 43:537-545

Del-Val E, Dirzo R (2003) Does ontogeny cause changes in the defensive strategies of the myrmecophyte Cecropia peltata? Plant Ecol 169: $35-41$

Freschet GT, Östlund L, Kichenin E, Wardle DA (2014) Aboveground and belowground legacies of native Sami land use on boreal forest in northern Sweden 100 years after abandonment. Ecology 95:963977

Gerzabek G, Oddou-Muratorio S, Hampe A (2017) Temporal change and determinants of maternal reproductive success in an expanding oak forest stand. J Ecol 105:39-48

Gossner MM, Brändle M, Brandl R, Bail J, Müller J, Opgenoorth L (2015) Where is the extended phenotype in the wild? The community composition of arthropods on mature oak trees does not depend on the oak genotype. PLoS One 10:e0115733

Guirado M, Pino J, Rodà F, Basnou C (2008) Quercus and Pinus cover are determined by landscape structure and dynamics in peri-urban Mediterranean forest patches. Plant Ecol 194:109-119

Hampe A, Pemonge MH, Petit RJ (2013) Efficient mitigation of founder effects during the establishment of a leading-edge oak population. $\mathrm{P}$ Roy Soc B Biol Sci 280:20131070

Ito M, Ozaki K (2005) Response of a gall wasp community to genetic variation in the host plant Quercus crispula: a test using half-sib families. Acta Oecol 27:17-24

Jactel H, Brockerhoff EG (2007) Tree diversity reduces herbivory by forest insects. Ecol Lett 10:835-848

Johnstone JF, Allen CD, Franklin JF, Frelich LE, Harvey BJ, Higuera PE, Schoennagel T (2016) Changing disturbance regimes, ecological memory, and forest resilience. Front Ecol Environ 14:369-378

Jombart T, Devillard S, Balloux F (2010) Discriminant analysis of principal components: a new method for the analysis of genetically structured populations. BMC Genetics: 11-94

Karban R, Shiojiri K, Huntzinger M, McCall AC (2006) Damageinduced resistance in sagebrush: volatiles are key to intra- and interplant communication. Ecology 87:922-930

Kauppi PE, Sandström V, Lipponen A (2018) Forest resources of nations in relation to human well-being. PLoS One 13:e0196248

Lämke JS, Unsicker SB (2018) Phytochemical variation in treetops: causes and consequences for tree-insect herbivore interactions. Oecologia 187:377-388

Laurance WF, Lovejoy TE, Vasconcelos HL, Bruna EM, Didham RK, Stouffer PC, Gascon C, Bierregaard RO, Laurance SG, Sampaio E (2002) Ecosystem decay of Amazonian forest fragments: a 22-year investigation. Conserv Biol 16:605-618

Lawton JH (1983) Plant architecture and the diversity of phytophagous insects. Annu Rev Entomol 28:23-39

Maguire DY, James PMA, Buddle CM, Bennett EM (2015) Landscape connectivity and insect herbivory: a framework for understanding tradeoffs among ecosystem services. Glob Ecol Conserv 4:73-84

Maron JL, Crone E (2006) Herbivory: effects on plant abundance, distribution and population growth. P Roy Soc B Biol Sci 273:25752584

McGeoch MA, Gaston KJ (2000) Edge effects on the prevalence and mortality factors of Phytomyza ilicis (Diptera, Agromyzidae) in a suburban woodland. Ecol Lett 3:23-29

Moreira X, Abdala-Roberts L, Parra-Tabla V, Mooney KA (2014) Positive effects of plant genotypic and species diversity on antiherbivore defenses in a tropical tree species. PLoS One 8:e105438
Moreira X, Abdala-Roberts L, Rasmann S, Castagneyrol B, Mooney KA (2016) Plant diversity effects on insect herbivores and their natural enemies: current thinking, recent findings, and future directions. Curr Opin Insect Sci 14:1-7

Moreira X, Glauser G, Abdala-Roberts L (2017) Interactive effects of plant neighbourhood and ontogeny on insect herbivory and plant defensive traits. Sci Rep UK 7:4047

Onoda Y, Schieving F, Anten NPR (2008) Effects of light and nutrient availability on leaf mechanical properties of Plantago major: a conceptual approach. Ann Bot 101:727-736

Pare PW, Tumlinson JH (1999) Plant volatiles as a defense against insect herbivores. Plant Physiol 121:325-331

Pearse IS (2011) The role of leaf defensive traits in oaks on the preference and performance of a polyphagous herbivore, Orgyia vetusta. Ecol Entomol 36:635-642

Perino A, Pereira HM, Navarro LM, Fernández N, Bullock JM, Ceauşu S, Cortés-Avizanda A, van Kinkl R, Kuemmerle T, Lomba A, Pe'er G, Plieninger T, Rey Benayas JM, Sandom CJ, Svenning JC, Wheeler HC (2019) Rewilding complex ecosystems. Science 364:eaav5570

Pugh TAM, Lindeskog M, Smith B, Poulter B, Arneth A, Haverd V, Calle L (2019) Role of forest regrowth in global carbon sink dynamics. Proc Natl Acad Sci 116(10):4382-4387

R Core Team (2017). R: A language and environment for statistical computing

Régolini M, Castagneyrol B, Dulaurent-Mercadal AM, Piou D, Samalens JC, Jactel H (2014) Effect of host tree density and apparency on the probability of attack by the pine processionary moth. For Ecol Manag 334:185-192

Ruíz-Carbayo H, Bonal R, Espelta JM, Hernández M, Pino J (2016) Community assembly in time and space: the case of Lepidoptera in a Quercus ilex L. savannah-like landscape. Insect Conserv Diver 10:21-31

Ruíz-Carbayo H, Bonal R, Pino J, Espelta JM (2018) Zero-sum landscape effects on acorn predation associated with shifts in granivore insect community in new holm oak (Quercus ilex) forests. Divers Distrib 24:521-534

Ruiz-Carbayo H, Pino J, Bonal R, James P M.A, Hampe A, MolownyHoras R, Espelta JM (2020) Insect herbivory in novel Quercus ilex L. forests: the role of landscape attributes, forest composition and host traits. V2. Dryad repository. [Dataset]. https://doi.org/10.5061/ dryad.rxwdbrv4v

Silfver T, Roininen H, Oksanen E, Rousi M (2009) Genetic and environmental determinants of silver birch growth and herbivore resistance. For Ecol Manag 257:2145-2149

Skoczylas DR, Muth NZ, Niesenbaum RA (2007) Contribution of insectivorous avifauna to top down control of Lindera benzoin herbivores at forest edge and interior habitats. Acta Oecol 32:337-342

Sokal RR, Rohlf FJ (1995) Biometry. W. H. H. Freeman and Company, New York

Song XP, Hansen MC, Stehman SV, Potapov PV, Tyukavina A, Vermote EF, Townshend JR (2018) Global land change from 1982 to 2016. Nature 560:639-643

Staudt M, Lhoutellier L (2007) Volatile organic compound emission from holm oak infested by gypsy moth larvae: evidence for distinct responses in damaged and undamaged leaves. Tree Physiol 27:14331440

Tack AJ, Ovaskainen O, Pulkkinen P, Roslin T (2010) Spatial location dominates over host plant genotype in structuring an herbivore community. Ecology 91:2660-2672

Tack AJ, Johnson MT, Roslin T (2012) Sizing up community genetics: it's a matter of scale. Oikos 121:481-488 
Thies C, Roschewitz I, Tscharntke T (2005) The landscape context of cereal aphid-parasitoid interactions. P Roy Soc B Biol Sci 272:203210

Tissot W, Kohler Y (2013) Integration of nature protection in forest policy in France. INTEGRATE Country Report. EFICENT-OEF, Freiburg

Tscharntke T, Steffan-Dewenter I, Kruess A, Thies C (2002) Characteristics of insect populations on habitat fragments: a mini review. Ecol Res 17:229-239

Valdés-Correcher E, Van Halder I, Barbaro L, Castagneyrol B, Hampe A (2019) Insect herbivory and avian insectivory in novel native oak forests: divergent effects of stand size and connectivity. For Ecol Manag 445:146-153

Vilà-Cabrera A, Espelta JM, Vayreda J, Pino J (2016) "New forests" from the twentieth century are a relevant contribution for $\mathrm{C}$ storage in the Iberian Peninsula. Ecosystems 20:130-143

Publisher's note Springer Nature remains neutral with regard to jurisdictional claims in published maps and institutional affiliations.

\section{Affiliations}

\section{Helena Ruiz-Carbayo ${ }^{1}$. Joan Pino ${ }^{1,2} \cdot$ Raúl Bonal $^{3}$ - Patrick M. A. James ${ }^{4} \cdot$ Arndt Hampe $^{5} \cdot$ Roberto Molowny-Horas $^{1}$. Josep Maria Espelta ${ }^{1,2}$}

CREAF, Bellaterra, E08193 Cerdanyola del Vallès, Catalonia, Spain

2 Universitat Autònoma de Barcelona, Bellaterra, E08193 Cerdanyola del Vallès, Catalonia, Spain
Group of Forestry Research, INDEHESA, University of Extremadura, Plasencia, Spain

4 University of Toronto, Toronto, ON M5S 3E8, Canada

5 Biogeco, INRA, University of Bordeaux, F-33610 Cestas, France 